\title{
Effect of using different methods in the construction of climate change scenarios: examples from Europe
}

\author{
Elaine Barrow $^{1, *}$, Mike Hulme ${ }^{1}$, Mikhail Semenov ${ }^{2}$ \\ ${ }^{1}$ Climatic Research Unit, University of East Anglia, Norwich NR4 7TJ, United Kingdom \\ ${ }^{2}$ IACR-Long Ashton Research Station, Department of Agricultural Sciences, University of Bristol, Bristol BS18 9AF, \\ United Kingdom
}

\begin{abstract}
To investigate the impacts of future climate change on agriculture in Europe and to aid the development of agricultural adaptation strategies, several scenarios of climate change were constructed and provided as input to crop-climate models at both broad and site-specific scales. These scenarios were based on results from a number of global climate model (GCM) experiments, including both equilibrium and transient climate change experiments. All GCMs provide 'internally consistent' scenarios of climate change, but at coarse horizontal spatial resolutions. Results from equilibrium experiments give no indication of the rate of climate change, whereas transient experiments simulate time-dependent climate change. Broad-scale climate change scenarios for Europe were constructed at $0.5^{\circ}$ latitude/longitude resolution using a Gaussian space-filtering routine. Site-specific scenarios at the daily timescale required by crop-growth simulation models were constructed using a stochastic weather generator in conjunction with GCM-derived information about possible future climate change. A regression technique to downscale broad-scale changes in temperature and precipitation means to specific sites was carried out at 2 European sites, Rothamsted, UK, and Seville, Spain. At other European sites, where crop-climate models were being run, the GCM-derived grid-box changes were used without downscaling. Use of a weather generator also enabled GCM-derived changes in climate variability to be incorporated into the scenarios by using the grid-box changes in the means and variances of the climate variables to perturb the parameters of the stochastic weather generator directly. The implications of using these different methods of climate change scenario construction for the resulting scenarios are discussed.
\end{abstract}

KEY WORDS: Climate change - Downscaling - Weather generators

\section{INTRODUCTION}

The increasing consensus that human pollution of the atmosphere is changing global climate, and will continue to do so in the future (IPCC 1996), is leading to an ever-increasing number of studies examining the sensitivity of natural and social systems to climate change. Such sensitivity studies can use simple scenarios of climate change, for example a mean annual temperature change of $2^{\circ} \mathrm{C}$ applied across a region to all the temperature data in a baseline dataset, to drive the environmental model in question. These studies may also, however, wish to use more sophisticated scenar-

\footnotetext{
•E-mail: e.barrow@uea.ac.uk
}

ios which describe detailed changes in daily weather variables for specific sites within the region. A number of different techniques have been developed in recent years to generate such scenarios, most of them using results from global climate model (GCM) experiments in some way or other. These GCM results may be used directly, may be downscaled to individual sites, or may be used in conjunction with stochastic weather generators (see Carter et al. 1994 for a brief review of these options).

The work reported here was undertaken as part of a longer project assessing the agricultural impacts of, and adaptations to, climate change in Europe (Harrison et al. 1995). This paper describes the construction of the climate change scenarios which were used by 
several crop modelling groups in Europe. The nature of the scenarios was thus partly determined by the demands of the crop modellers. Four separate components of the scenario construction process are examined and illustrated: the choice of which GCM to use; the application of a downscaling technique; the linking of GCM results to a weather generator; and the incorporation of changes in climate variability in addition to changes in mean climate. The impacts of these scenarios on agriculture in Europe are discussed in the following papers of this issue.

Climate change scenarios were constructed at 2 temporal and 2 spatial scales, i.e. monthly changes at $0.5^{\circ}$ latitude/longitude resolution across Europe and daily changes at specific sites within Europe. Scenarios with high spatial resolution may be constructed using one of the downscaling techniques currently available (e.g. Wigley et al. 1990, Hay et al. 1992, Matyasovszky et al. 1993) whilst high temporal resolution may be achieved either by applying GCM-derived changes to the historical record (e.g. Mearns et al. 1992, Kenny et al. 1993), or by use of a stochastic weather generator (e.g. Bardossy 1994, Barrow \& Semenov 1995). It is also important to include changes in climate variability in the scenarios since recent work on the sensitivity of cropgrowth simulation models to changes in climate variables has clearly shown that changes in climate variability can have a significant effect on crop growth and associated agricultural risk (Semenov \& Porter 1994 . 1995, Mearns et al. 1996).

The climate change scenarios used in this study were constructed using results from 2 equilibrium and 2 transient GCM climate change experiments: the United Kingdom Meteorological Office low resolution GCM equilibrium experiment (UKLO; Wilson \& Mitchell 1987); the UK Meteorological Office high resolution GCM equilibrium experiment (UKHI; Mitchell et al. 1990); the UK Meteorological Office GCM transient experiment (UKTR; Murphy 1995, Murphy \& Mitchell 1995); and the Geophysical Fluid Dynamics Laboratory (Princeton University, USA) GCM transient experiment (GFDL; Manabe et al. 1991, 1992). None of these GCM experiments include the effects of sulphate aerosols on the radiative forcing of climate and therefore the scenarios constructed here and used by the crop modellers do not consider how important these effects may be in the future. By definition, equilibrium experiments simulate a steady-state climate resulting from an instantaneous doubling of atmospheric $\mathrm{CO}_{2}$ and hence illustrate the magnitude and pattern of the greenhouse gas signal. Transient experiments, on the other hand, simulate a climate responding to incremental increases in greenhouse gas concentrations, a climate which is never in equilibrium. In these latter experiments the greenhouse gas signal is obscured by the noise of natural climate variability and is harder to define. Equilibrium GCM experiments were included in this study to provide a link between the work reported here and that undertaken in a previous project investigating the impacts of climate change on the agricultural and horticultural potential of Europe (Kenny et al. 1993). Table 1 indicates some of the main characteristics of these GCMs.

The broad-scale European scenarios were constructed at $0.5^{\circ}$ latitude/longitude resolution for a number of climate variables. Downscaling of GCM gridbox information to specific sites was undertaken at Rothamsted, UK, and Seville, Spain, whilst at other European locations where climate change scenarios were required GCM grid-box data were used without downscaling. For both types of site-specific scenario a stochastic weather generator, the Long Ashton Research Station. Weather Generator (LARS-WG, based on Racsko et al. 1991), was used to produce data at the daily timescale required by the crop-climate modellers. Using a stochastic weather generator also meant that changes in climate variability could be considered.

The climate change scenarios constructed here reflect different global-mean temperature changes. Scenarios based on results from an equilibrium experiment, which represent climate at some unspecified point in the future, will give much greater changes compared to those from an early decade of one of the transient experiments, which represent climate in the earlier years of the next century. For example, the global-mean warmings of UKLO and UKHI are 5.2 and $3.5^{\circ} \mathrm{C}$, respectively, compared to only $0.7^{\circ} \mathrm{C}$ for the earlier of the 2 decades of the transient experiments used. Differences in crop model results may therefore be due

Table 1. Characteristics of the GCMs used in the construction of climate change scenarios

\begin{tabular}{|c|c|c|c|c|c|}
\hline \multirow[t]{2}{*}{ GCM } & \multicolumn{2}{|c|}{$\mathrm{CO}_{2}$ concentration (ppmv) } & \multirow[t]{2}{*}{ Type of model } & \multirow{2}{*}{$\begin{array}{l}\text { Atmospheric resolution } \\
\left({ }^{\circ} \text { latitude by }{ }^{\circ} \text { longitude }\right)\end{array}$} & \multirow{2}{*}{$\begin{array}{c}\text { Climate sensitivity } \\
\left({ }^{\circ} \mathrm{C}\right)\end{array}$} \\
\hline & Control & Perturbed & & & \\
\hline UKLO & 323 & 646 & Gridded & $5 \times 7.5$ & 5.2 \\
\hline UKHI & 323 & 64.6 & Gridded & $2.5 \times 3.75$ & 3.5 \\
\hline UKTR & 323 & $1 \% \mathrm{yr}^{-1}$ compounded & Gridded & $2.5 \times 3.75$ & 2.7 (estimated) \\
\hline GFDL & 300 & $1 \% \mathrm{yr}^{-1}$ compounded & Spectral & $4.5 \times 7.5$ & 3.7 \\
\hline
\end{tabular}


to the different global-mean warmings of the scenarios rather than to the different patterns of climate change simulated by the GCMs or to the effects of different scenario construction techniques. Crop model results should only be directly compared if the climate change scenarios used as input have the same global-mean warming, e.g. UKTR Years $31-40$ and GFDL Years $25-34$

This paper describes the construction of climate change scenarios from equilibrium and transient GCM experiments first at the broad scale and then at individual sites. The regression downscaling technique used to determine site-specific climate from that of a larger region is discussed. How climate variability is incorporated into the scenarios follows, before the effects of the different methods of scenario construction are described in more detail.

\section{CONSTRUCTION OF CLIMATE CHANGE SCENARIOS}

The scenarios constructed here from equilibrium and transient GCM experiments represent 4 different levels of global warming $\left(0.68,1.76,3.5\right.$ and $\left.5.2^{\circ} \mathrm{C}\right)$ which will be realised progressively during the 21 st and 22 nd centuries. To determine the dates by which these changes may occur the reader is directed to the recent report by the Intergovernmental Panel on Climate Change (IPCC 1996)

\subsection{Scenarios using GCM equilibrium experiments}

Climate change scenarios were produced from both UKLO and UKHI by calculating the $2 \times \mathrm{CO}_{2}$ minus $1 \times \mathrm{CO}_{2}$ difference fields for mean monthly maximum and minimum temperature, precipitation, vapour pressure, incident solar radiation and wind speed. For all climate variables except precipitation and wind speed the absolute differences were used, whereas for these 2 variables the percentage differences were calculated. These fields represent the model-simulated difference between the 'present' climate and the equilibrium climate at some point in the future following an instantaneous doubling of atmospheric $\mathrm{CO}_{2}$ concentration. The exact date by which these changes might be realised is unknown for 2 reasons. First, the lag between the radiative forcing of the atmosphere and the ocean response to that forcing may be many centuries and is not directly simulated by the GCM. Second, it is not known when $\mathrm{CO}_{2}$ concentrations will have doubled, or when equivalent $\mathrm{CO}_{2}$ concentrations will have increased to levels where their radiative forcing is equivalent to that of a doubling of $\mathrm{CO}_{2}$ over pre- sent-day levels. The equilibrium changes in climate simulated by UKLO and UKHI are not expected to occur before the latter years of the next century at the earliest, if at all (Kattenberg et al. 1996)

\subsection{Scenarios using GCM transient experiments}

Although the $\mathrm{CO}_{2}$ forcing scenarios of UKTR and GFDL are more realistic than those used in the equilibrium experiments, it is still not possible to ascribe actual calendar years to the years of the perturbed integrations of these transient experiments for a number of reasons (see Hasselmann et al. 1993, Viner \& Hulme 1993). One problem with GCM transient experiments is drift in the control integration. Over the $75 \mathrm{yr}$ period of the control integration of UKTR, for example, a noticeable deviation in global temperature occurs (approximately $1^{\circ} \mathrm{C}$ ) from the initial $10 \mathrm{yr}$ average. One of the contributing factors to this drifting climate is the errors which slowly build up throughout the GCM integration. No GCM is a perfect representation of the global climate system and so over time errors slowly accumulate. Drift may also occur as a result of longterm natural variability (>100 yr) which, due to the short nature of the control integration, cannot be fully defined. Also, if there has been insufficient 'spin-up' of the coupled ocean-atmosphere system before the experiment is begun, the initial model climate is only at quasi-rather than full equilibrium. For the scenarios described here, the change fields were calculated using the difference between a period in the climate change integration and the corresponding years of the control integration. This definition is appropriate if one assumes that both the control and climate change integrations exhibit similar drift and long-term variability.

Only decadal-mean data were available from the UKTR experiment. Two decades were selected: the model Years 31-40 to be representative of the climate about half-way through the experiment, and model Years 66-75, the last decade of the experiment. The global-mean temperature changes associated with these decades in UKTR are 0.68 and $1.76^{\circ} \mathrm{C}$, respectively. Decades were selected from the GFDL experiment which had the same global-mean temperature change as those of the 2 UKTR decades, namely model Years 25-34 and 55-64. The regional climatology of a transient GCM experiment often exhibits large medium-term (10 to 20 yr) variability and hence climate statistics can differ greatly between successive decades of an experiment. This means that scenarios of the time development of climate change may not (indeed, almost certainly do not) solely reflect greenhouse gas-induced warming; large changes in mean temperature may be due as much to the natural cli- 
mate variability simulated by the model as to greenhouse gas-induced climate change (see February UKTR decade 31-40 cf. UKTR decade 66-75 in Table 6 as an example of this). One way of smoothing out these decadal variations would be to use 30 yr average data from GCMs.

\section{CONSTRUCTION OF BROAD-SCALE SCENARIOS}

As mentioned earlier, either absolute or percentage difference fields were calculated for a number of climate variables on a monthly basis for both the equilibrium and transient GCM experiments. These fields were interpolated from their original horizontal spatial resolutions to a resolution of $0.5^{\circ}$ latitude by $0.5^{\circ}$ longitude using a Gaussian space-filtering routine (Santer 1988). This interpolation was undertaken to allow the GCM changes to be easily applied to a 1961-1990 European climatology (Hulme et al. 1995). Changes in mean temperature $\left({ }^{\circ} \mathrm{C}\right)$ and precipitation (\%) in spring are illustrated in Figs. $1 \& 2$. This season was selected for illustration as it is the key season affecting agricultural production in most of Europe.

\subsection{Comparison of broad-scale scenarios}

There are a number of reasons for the differences amongst the broad-scale scenarios which should be borne in mind when comparing the change fields (for example, those illustrated in Figs. 1 \& 2). UKLO, UKHI and UKTR are GCM experiments undertaken at the same modelling centre, namely the UK Meteorological Office. In the case of the equilibrium experiments, UKHI uses an updated and improved version of the model used in UKLO in which the spatial resolution has also been increased (Table 1). UKTR, a transient experiment, uses a further update of the model with the coupling of a fully 3-dimensional ocean GCM. The 2 decades of this experiment are readily comparable, with the differences in climate change pattern between the decades being due to the differing relative contributions of natural variability and the greenhouse gas signal to climate change. The GFDL transient experiment uses a model developed at a different modelling centre, the Geophysical Fluid Dynamics Laboratory, which therefore is constructed differently from the UK Meteorological Office model.

One way of comparing these broad-scale scenarios is by calculating the spatial pattern correlation coefficients between pairs of change fields. This gives an idea of how similar the patterns of change are from each experiment, in spite of the different forcing sce- narios and model complexities. The first step in this process is the standardisation of the change fields with respect to their climate sensitivity (in the case of the equilibrium experiments) and to the global-mean temperature change of the appropriate decade (for the transient experiments) to give the patterns of change per degree of global warming. Seasonal pattern correlation coefficients for mean temperature and precipitation change are shown in Tables $2 \& 3$, respectively.

The spatial pattern correlation coefficients for temperature tend to be higher amongst the UK Meteoro-

Table 2. Intermodel spatial pattern correlation coefficients mean temperature change

\begin{tabular}{|lcccccc}
\hline & UKLO & UKHI & UKTR & UKTR & GFDL & GFDL \\
& & & $31-40$ & $66-75$ & $25-34$ & $55-64$ \\
\hline Winter & & & & & & \\
UKLO & 1.00 & & & & & \\
UKHI & 0.53 & 1.00 & & & & \\
UKTR & 0.78 & 0.68 & 1.00 & & & \\
$31-40$ & & & & & & \\
UKTR & 0.90 & 0.53 & 0.88 & 1.00 & & \\
$66-75$ & & & & & & \\
GFDL & 0.52 & -0.65 & -0.68 & -0.64 & 1.00 & \\
$25-34$ & & & & & & \\
GFDL & 0.43 & 0.23 & 0.20 & 0.37 & -0.12 & 1.00 \\
$55-64$ & & & & & & \\
SPring & & & & & & \\
UKLO & 1.00 & & & & & \\
UKHI & 0.42 & 1.00 & & & & \\
UKTR & 0.83 & 0.19 & 1.00 & & & \\
$31-40$ & & & & & & \\
UKTR & 0.88 & 0.54 & 0.89 & 1.00 & & \\
$66-75$ & & & & & & \\
GFDL & 0.07 & 0.33 & 0.04 & 0.17 & 1.00 & \\
$25-34$ & & & & & & \\
GFDL & -0.12 & 0.44 & -0.28 & -0.08 & 0.49 & 1.00 \\
$55-64$ & & & & & & \\
Summer & & & & & & \\
UKLO & 1.00 & & & & & \\
UKHI & 0.30 & 1.00 & & & & \\
UKTR & 0.43 & -0.12 & 1.00 & & & \\
$31-40$ & & & & & & \\
UKTR & 0.55 & 0.02 & 0.85 & 1.00 & & \\
$66-75$ & & & & & & \\
GFDL & 0.14 & 0.17 & 0.35 & 0.32 & 1.00 & \\
$25-34$ & & & & & & \\
GFDL & 0.28 & 0.04 & 0.27 & 0.42 & 0.23 & 1.00 \\
$55-64$ & & & & & & \\
Autumn & & & & & & \\
UKLO & 1.00 & & & & & \\
UKHI & -0.01 & 1.00 & & & & \\
UKTR & 0.54 & 0.01 & 1.00 & & & \\
$31-40$ & & & & & & \\
UKTR & 0.63 & 0.13 & 0.94 & 1.00 & & \\
$66-75$ & & & & & & \\
GFDL & 0.19 & 0.51 & 0.22 & 0.35 & 1.00 & \\
$25-34$ & & & & & & \\
GFDL & 0.17 & -0.39 & 0.42 & 0.32 & -0.02 & \\
$55-64$ & & & & & & \\
\hline
\end{tabular}



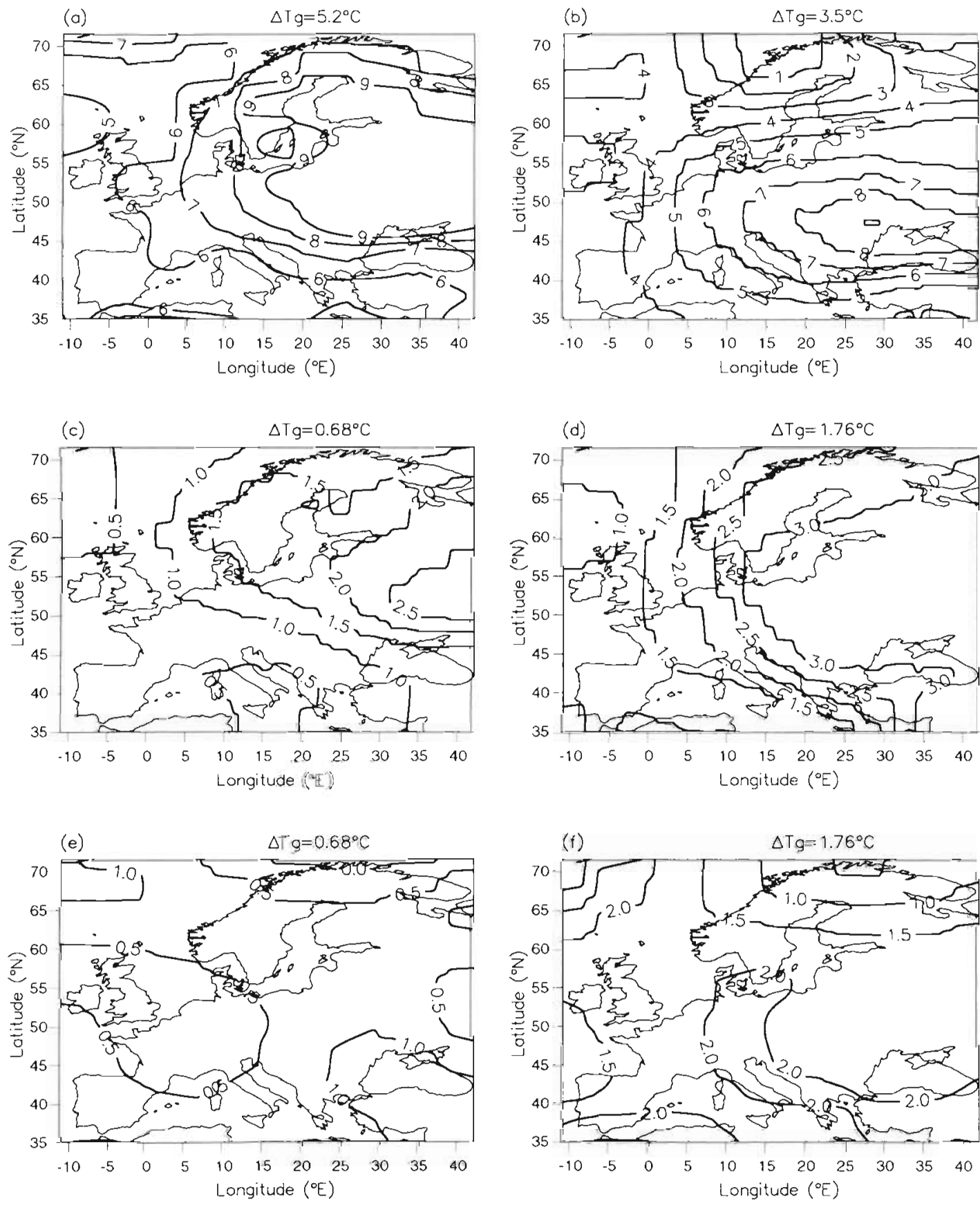

Fig. 1. Spring (MAM) temperature change $\left({ }^{\circ} \mathrm{C}\right.$ ): (a) UKLO, (b) UKHI, (c) UKTR decade 31-40, (d) UKTR decade 66-75, (e) GFDL decade 25-34, (f) GFDL decade 55-64. The global-mean temperature change ( $\Delta T_{\mathrm{g}}$ ) associated with each scenario is indicated at the top of each figure

logical Office experiments than between the 2 decades of the GFDL experiment (Table 2). The 2 decades of the UKTR experiment appear to be highly correlated in all seasons, indicating that there is relatively little difference in the pattern of mean temperature change between these 2 decades. These high correlations suggest that in this experiment the greenhouse gas signal may be evident as early as decade 31-40. This is in contrast to the 2 decades of the GFDL experiment which only show a degree of consistency in spring. Both decades of the UKTR experiment are more highly correlated with the UKLO experiment than with UKHI. There does not appear to be any consistent pattern between the GFDL decades and any of the UK Meteorological Office experiments. 

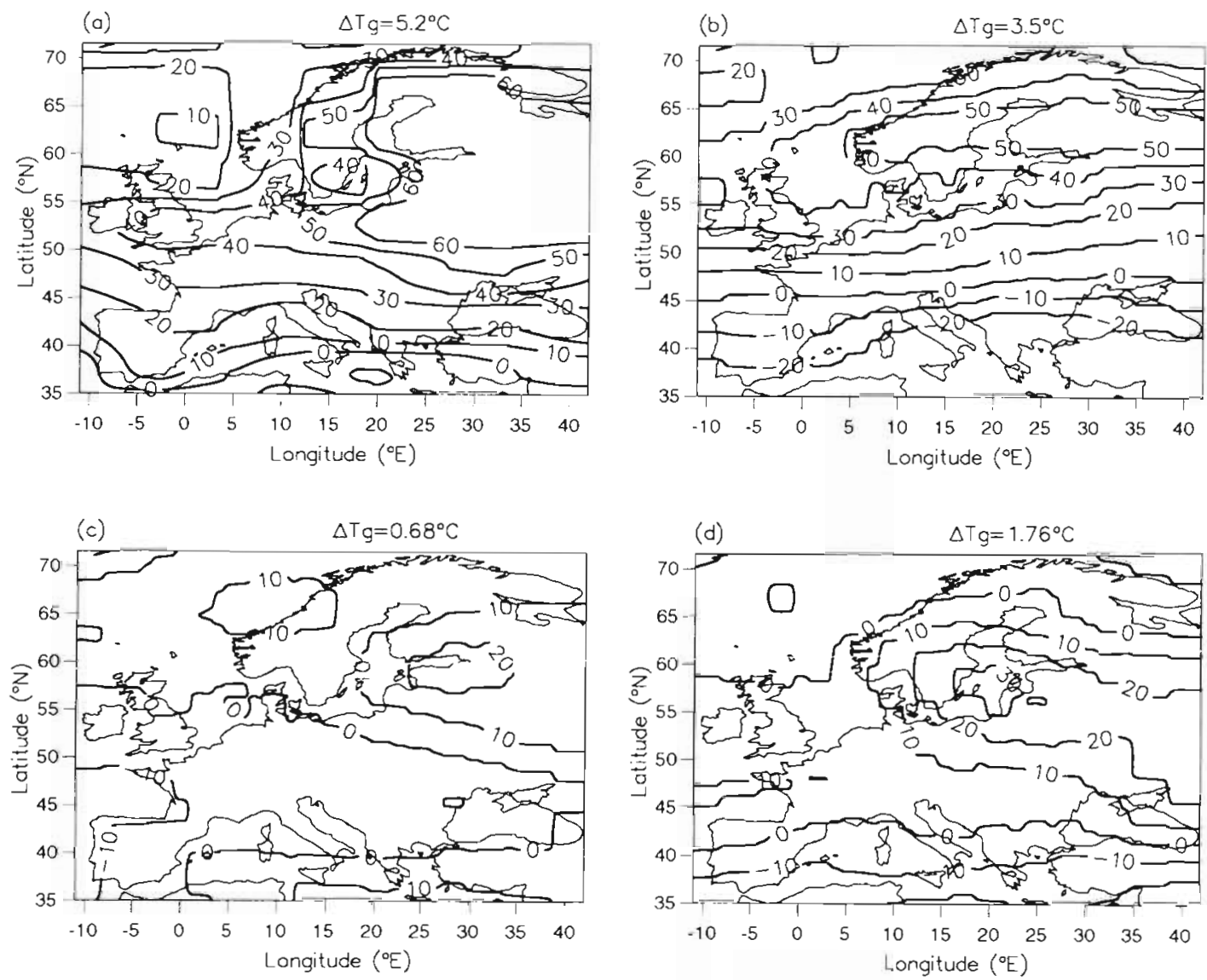

(e)

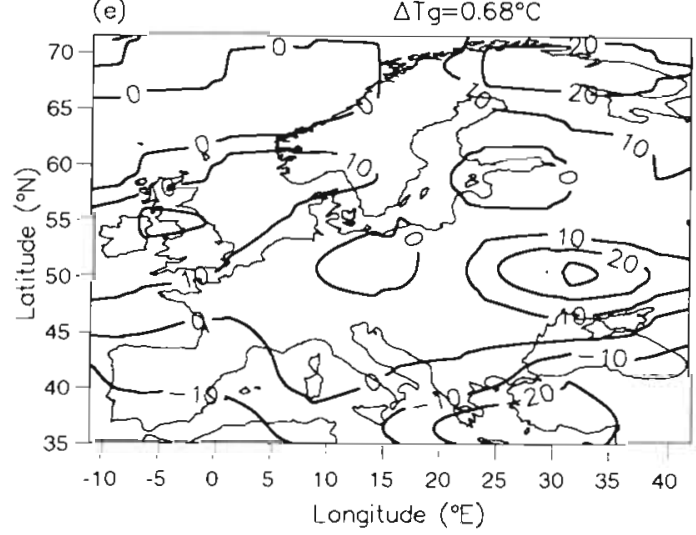

(f)

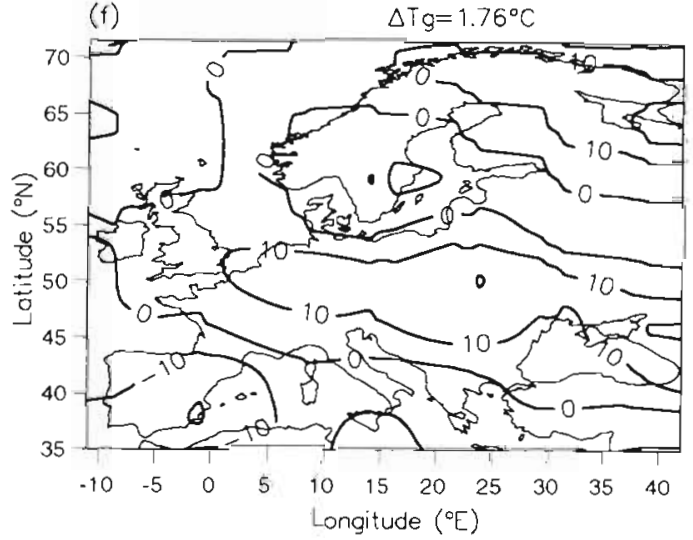

Fig. 2. Spring (MAM) precipitation change (\%): (a) UKLO, (b) UKHI, (c) UKTR decade 31-40, (d) UKTR decade 66-75, (e) GFDL decade 25-34, (f) GFDL decade 55-64. The global-mean temperature change $\left(\Delta T_{g}\right)$ associated with each scenario is indicated at the top of each figure

In the case of precipitation change, Table 3 indicates broadly similar results although the correlation coefficients are not as high as those of mean temperature change. This is as expected since, in general, precipitation change patterns show greater inter-model differences than do temperature change patterns (Kattenberg et al. 1996). The 2 UKTR decades are again well correlated except in spring. The UKLO experi- ment correlates well with both UKHI and the last decade of the UKTR experiment. Correlations amongst the equilibrium experiments and the earlier decade of UKTR are also relatively high, but generally lower than those with the latter decade of this experiment. There is little consistency in the pattern of precipitation change between the 2 GFDL decades except in spring, when the correlation coefficient is 0.51 . The 
Table 3. Intermodel spatial pattern correlation coefficients precipitation change

\begin{tabular}{|c|c|c|c|c|c|c|}
\hline & UKLO & UKHI & $\begin{array}{l}\text { UKTR } \\
31-40\end{array}$ & $\begin{array}{l}\text { UKTR } \\
66-75\end{array}$ & $\begin{array}{l}\text { GFDL } \\
25-34\end{array}$ & $\begin{array}{l}\text { GFDL } \\
55-64\end{array}$ \\
\hline \multicolumn{7}{|l|}{ Winter } \\
\hline UKLO & 1.00 & & & & & \\
\hline UKHI & 0.76 & 1.00 & & & & \\
\hline $\begin{array}{l}\text { UKTR } \\
31-40\end{array}$ & 0.57 & 0.71 & 1.00 & & & \\
\hline $\begin{array}{l}\text { UKTR } \\
66-75\end{array}$ & 0.73 & 0.67 & 0.74 & 1.00 & & \\
\hline $\begin{array}{l}\text { GFDL } \\
25-34\end{array}$ & -0.34 & -0.47 & -0.24 & -0.40 & 1.00 & \\
\hline $\begin{array}{l}\text { GFDL } \\
55-64\end{array}$ & 0.45 & 0.22 & 0.23 & 0.40 & 0.06 & 1.00 \\
\hline \multicolumn{7}{|l|}{ Spring } \\
\hline UKLO & 1.00 & & & & & \\
\hline UKHI & 0.65 & 1.00 & & & & \\
\hline $\begin{array}{l}\text { UKTR } \\
31-40\end{array}$ & 0.45 & 0.45 & 1.00 & & & \\
\hline $\begin{array}{l}\text { UKTR } \\
66-75\end{array}$ & 0.72 & 0.45 & 0.17 & 1.00 & & \\
\hline $\begin{array}{l}\text { GFDL } \\
25-34\end{array}$ & 0.58 & 0.61 & 0.02 & 0.37 & 1.00 & \\
\hline $\begin{array}{l}\text { GFDL } \\
55-64\end{array}$ & 0.47 & 0.29 & 0.01 & 0.25 & 0.51 & 1.00 \\
\hline \multicolumn{7}{|c|}{ Summer } \\
\hline UKLO & 1.00 & & & & & \\
\hline UKHI & 0.66 & 1.00 & & & & \\
\hline $\begin{array}{l}\text { UKTR } \\
31-40\end{array}$ & 0.76 & 0.65 & 1.00 & & & \\
\hline $\begin{array}{l}\text { UKTR } \\
66-75\end{array}$ & 0.70 & 0.93 & 0.70 & 1.00 & & \\
\hline $\begin{array}{l}\text { GFDL } \\
25-34\end{array}$ & 0.02 & 0.26 & -0.14 & 0.28 & 1.00 & \\
\hline $\begin{array}{l}\text { GFDL } \\
55-64\end{array}$ & 0.50 & 0.44 & 0.35 & 0.46 & -0.16 & 1.00 \\
\hline \multicolumn{7}{|c|}{ Autumn } \\
\hline UKLO & 1.00 & & & & & \\
\hline UKHI & 0.84 & 1.00 & & & & \\
\hline $\begin{array}{l}\text { UKTR } \\
31-40\end{array}$ & 0.67 & 0.71 & 1.00 & & & \\
\hline $\begin{array}{l}\text { UKTR } \\
66-75\end{array}$ & 0.82 & 0.76 & 0.69 & 1.00 & & \\
\hline $\begin{array}{l}\text { GFDL } \\
25-34\end{array}$ & 0.03 & 0.13 & 0.15 & 0.06 & 1.00 & \\
\hline $\begin{array}{l}\text { GFDL } \\
55-64\end{array}$ & 0.47 & 0.60 & 0.61 & 0.54 & 0.35 & 1.00 \\
\hline
\end{tabular}

pattern of precipitation change in the earlier decade of the GFDL experiment is most consistent with the other 5 experiments in spring. The latter decade of this experiment is most consistent with the pattern of change of the UK Meteorological Office models in the autumn.

Clearly, then, not only are the extracted climate change fields from the different experiments associated with different levels of global warming (between $0.68^{\circ} \mathrm{C}$ and $5.2^{\circ} \mathrm{C}$ ), but the actual patterns of climate change are quite variable from model-to-model and from decade-to-decade. The next section considers how these diverse broad-scale scenarios of climate change may be related to individual locations within Europe.

\section{CONSTRUCTION OF SITE-SPECIFIC SCENARIOS}

In order for climate change scenarios to be of use in crop-growth simulation models, it is necessary to provide daily weather data on a site-specific basis. A stochastic weather generator was used to serve this purpose. The weather generator used in this study, LARS-WG, was based on that described in Racsko et al. (1991), to which modifications were made to facilitate its application across Europe and in order to match the output from weather generator to the meteorological input required by crop-growth simulation models.

The first step in the production of daily weather data using LARS-WG was the calibration of the generator itself. In this process observed daily data (usually $30 \mathrm{yr}$ ) were used to calculate the site-specific parameters of the generator, namely daily precipitation intensity, wet and dry series length, temperature and radiation means and standard deviations for both wet and dry days. Obviously the more observed data available to calibrate the weather generator, the more robust the parameters calculated will be. These parameters were then used to generate $30 \mathrm{yr}$ of synthetic weather data (referred to as 'Base' in Tables 4 to 11). Generally, LARS-WG performed well in simulating the magnitude and annual cycle of the main weather statistics. including those climate extremes relevant to agriculture (Semenov \& Barrow 1996).

Site-specific climate change scenarios required sitespecific changes derived from GCM output. Coarse resolution GCM grid-box changes in mean temperature and precipitation were downscaled at 2 sites in Europe. Unfortunately a robust procedure to downscale changes in the variability of the weather variables was not available. To investigate the effect of these changes, the GCM grid-box changes in mean and variability were used directly without downscaling at the rest of the European sites where scenarios were required. In both cases, the GCM-derived changes were used to perturb the parameters of LARS-WG and $30 \mathrm{yr}$ of daily scenario data were then generated.

\subsection{Scenarios with downscaling}

The coarse spatial resolution of GCMs (typically 250 to $500 \mathrm{~km}$ ) leads to approximations in the spatial representation of meteorological variables and, hence, to 
the exclusion of local and regional weather phenomena. In order to produce scenarios of climate change at the site scale, coarse resolution data can be 'downscaled' to the scales required in work on regional impacts. The current development of High Resolution Limited Area Models (HRLAMs), operating at about $50 \mathrm{~km}$ resolution, may constitute an alternative technique to downscaling for the provision of high spatial resolution scenarios of climate change. At the moment, however, only limited data are available from these models. Downscaling involves the development of relationships between the coarse- and local-scale data for the climate variables concerned. There are a number of methodologies currently in use, including circulation patterns (e.g. Bardossy \& Caspary 1991, Matyasovszky et al. 1993, Jones \& Conway 1995) and regression techniques (e.g. Kim et al. 1984, Karl et al. 1990, Wigley et al. 1990, von Storch et al. 1993). Both sets of methods use existing instrumental databases to determine the relationships between large-scale and local climate. It is then assumed (rather than proved) that these relationships will be valid under the future climate. Regression techniques develop statistical relationships between local station data and grid-box area average values of, say, temperature and precipitation and other meteorological variables. In the circulation pattern approach atmospheric circulation is classified according to type and relationships are then determined between the type (for example, cyclonic) and the climate variable (for example, precipitation).

Work by Hulme et al. (1993) has shown, however, that there are a number of reservations to be considered when using circulation patterns as part of climate change studies. These include problems of GCMs in simulating the correct frequencies of weather types and also their failure to simulate some of the observed relationships between particular circulation patterns and, for example, temperature and precipitation. For this project, downscaling was undertaken at 2 sites in Europe (Rothamsted, UK, and Seville, Spain) using the regression approach. Regression relationships were calculated between local station data (mean temperature and precipitation) and grid-box-scale monthly anomalies of mean sea level pressure (MSLP), the north-south and east-west pressure gradients, temperature and precipitation. These relationships were based on anomalies from the long-term mean in order to facilitate the use of the GCM change fields in the equations. If the regression models explain a high proportion of the variance in the observed data then the models can be used to calculate the site-specific changes in temperature and precipitation using the GCM-derived grid-box information, provided that the scenario changes in these variables are within the observed range of the data used to develop the regression models.
The multiple correlation coefficient, however, invariably overestimates the predictive power of the regression equation. To try and overcome this to some extent, the data were arbitrarily split into calibration and verification sets. The verification correlation coefficient provides a more reliable guide to the predictive power of the equations. This procedure was, however, hampered by a lack of data. At least 20 yr of data are required to develop equations that are robust in any way, which means that the sample used for verification was small and, therefore, may be unrepresentative of the predictive power of the equations. The regression equations were of the form:

$$
\begin{aligned}
T_{\text {site }}\left(\text { or } P_{\text {site }}\right)= & \text { constant }+a T_{\text {area }}+b P_{\text {area }}+c M S L P+ \\
& d \Delta p_{\text {ns }}+e \Delta p_{\text {ew }}
\end{aligned}
$$

where $T_{\text {site }}$ is the temperature anomaly and $P_{\text {site }}$ the precipitation anomaly at the site in question, $T_{\text {area }}$ is the areal temperature anomaly, $P_{\text {area }}$ is the areal precipitation anomaly, MSLP is the mean sea level pressure anomaly and $\Delta p_{n s}$ and $\Delta p_{\text {ew }}$ are the north-south and east-west pressure gradient anomalies respectively. The coefficients $a, b, c, d$ and $e$ and the constant are calculated in the regression procedure.

The first step in the downscaling process was the calculation of the observed areal means corresponding to the grid-box areas of UKHI and UKTR. Fig. 3 indicates the sites used in this process. Both the Rothamsted and Seville sites were included in the calculation of the areal means because of the small number of sites available in the UK and the large amount of missing data in the Spanish data records. For temperature, anomalies from the 1961-1990 means were calculated for each station in the grid box. These site anomalies were then simply averaged to produce an areally-averaged value. For Rothamsted, the areal precipitation anomalies were calculated in a similar manner, but for Seville a Thiessen fitting procedure was used to overcome the large amount of missing data in the record. This method produces grid-box estimates of precipitation and fills in missing values by considering precipitation anomalies of neighbouring stations within a specified search radius (see Hulme 1994). Although in reality the grid boxes representing Rothamsted and Seville contain some ocean, they are considered to be land boxes by the GCM. Hence, the areal means were calculated using only land-based stations. Once the grid-box precipitation values had been calculated, the precipitation anomalies from the 1961-1990 means were determined.

The data were split into 2 time periods in order, first. to calibrate the regression equations and then, second, to verify their performance. For both Rothamsted and Seville the regression analyses were undertaken for each month using the site temperature and precipita- 

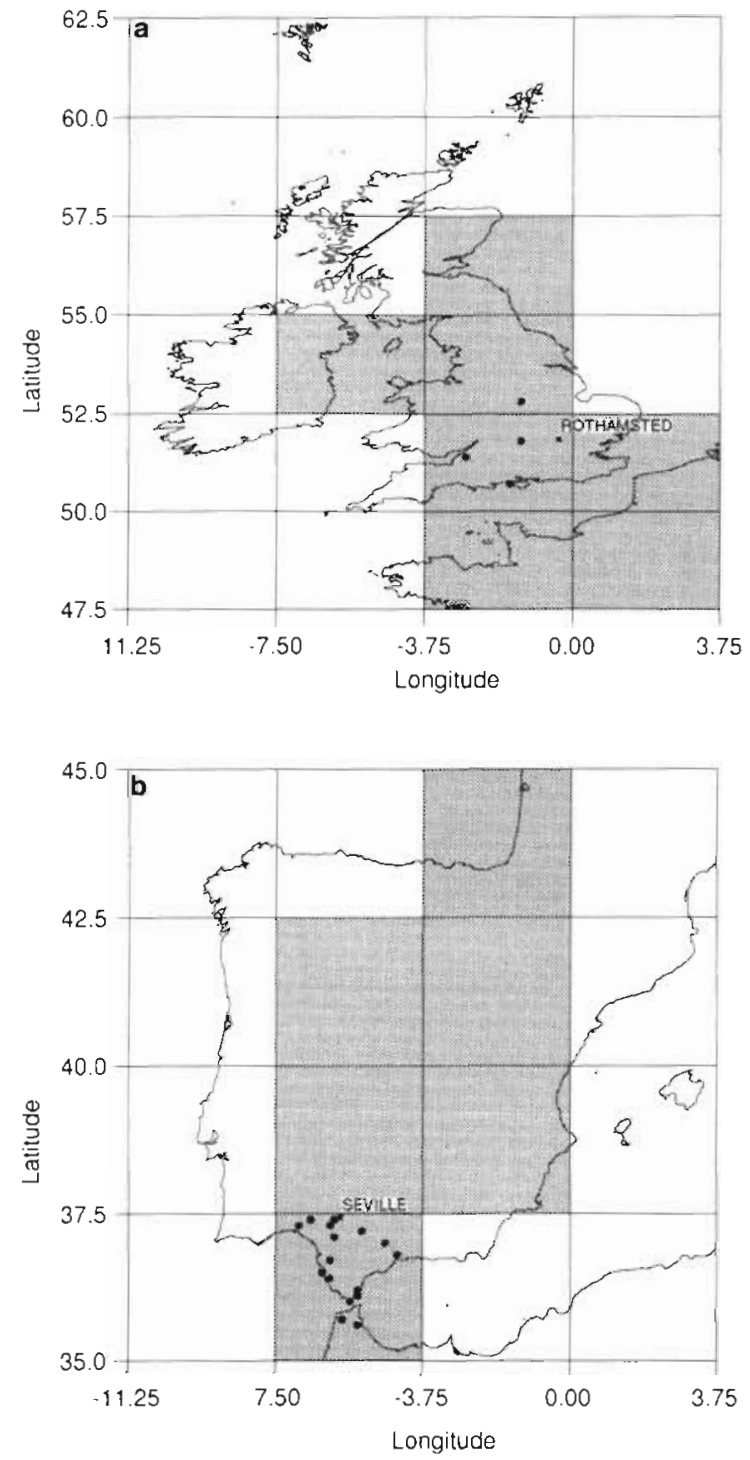

Fig. 3. Location of the stations used in the calculation of observed grid-box temperature and precipitation anomalies: (a) Rothamsted, UK, (b) Seville, Spain. Shaded cells correspond to the land grid boxes of UKHI and UKTR. Both Rothamsted and Seville are indicated by the small black squares. The other stations used are depicted by black circles

tion anomalies as predictands and the grid-box-averaged anomalies of temperature, precipitation, MSLP, north-south and east-west pressure gradients as predictors. The performance of the regression models is illustrated in Fig. 4 and the verification results in Fig. 5. For both sites the models generally performed better for temperature than for precipitation, especially in summer. For Seville the modelling of precipitation was particularly poor in July. However, as precipitation is small in this month, the poor performance of the model is not necessarily important; more worrying is the negative correlation in the verification result obtained in
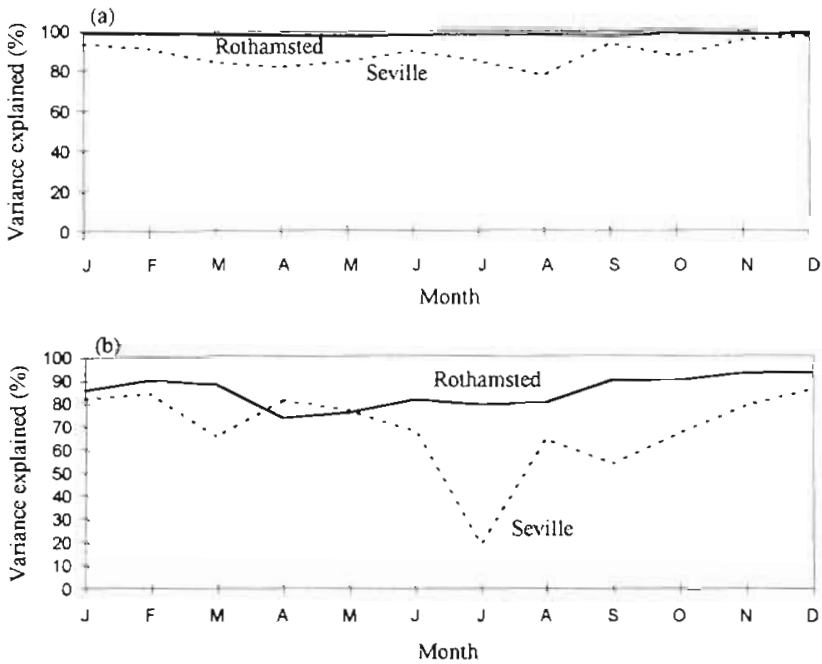

Fig. 4. Calibration of the regression models for Rothamsted and Seville (based on 1961-1983 and 1961-1990 observed data, respectively). (a) Percent variance in observed mean temperature explained by the regression models; (b) percent variance in observed precipitation explained by the regres. sion models
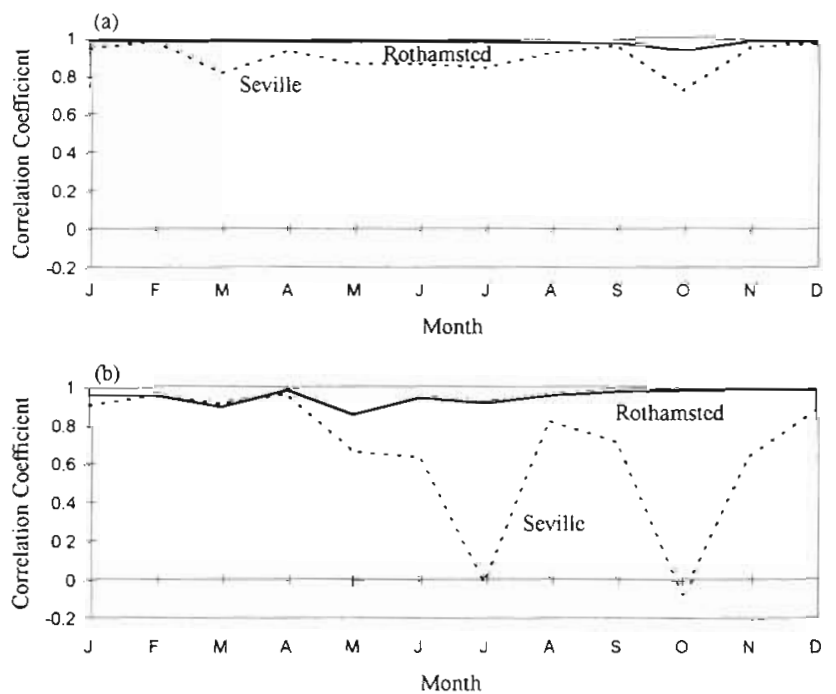

Fig. 5. Verifjcation of the regression models for Rothamsted and Seville (based on 1984-1990 and 1951-1960 observed data, respectively). (a) Correlation coefficient between observed mean temperature and that predicted by the regression models; (b) correlation coefficient between observed precipitation and that predicted by the regression models

October (Fig. 5). Further examination of the 1951-1960 precipitation data used to verify the regression models indicated that there was a high positive anomaly in October 1960 which the regression model failed completely to simulate. Also, for 6 of the 10 years, the model predicted anomalies of the opposite sign compared to the actual observed data. This indicates that although the regression model explained $67.4 \%$ of the 
variability of the 1961-1990 observed data in October, the majority of the 1951-1960 data fell outside of the range explained by the model. More reliable results may have been obtained if the calibration and verification datasets had been randomly selected rather than simply dividing the complete dataset into 2 . However, the poor performance of the precipitation regression models for Seville is not surprising given the rare occurrence of precipitation in mid-summer and the highly localised and sometimes very heavy rainfall which occurs in autumn. Although there were reservations about using a number of these regression models in the downscaling procedure because of their poor performance, the process was completed to enable the production of climate change scenarios for Seville.

The next step in the downscaling procedure was the calculation of the changes in mean temperature, precipitation, MSLP, and north-south and east-west pressure gradients at both sites corresponding to UKHI and to the 2 decades of the UKTR experiment. The GCMderived changes are $10 \mathrm{yr}$ mean anomalies for both UKHI and UKTR rather than anomalies calculated from individual years. It would have been more appropriate to apply anomalies of the individual years simulated by the GCM, since this is the timescale at which the regression models were developed, but at the time that this work was undertaken only the decadal-mean values were available. On comparison of the GCMderived anomalies with the anomaly ranges derived from the observed data and used to calculate the regression models, it was apparent that for UKHI most of the mean temperature changes fell outside of the anomaly ranges for both Rothamsted and Seville. For either decade of the UKTR experiment this was the case for about half of the time. For the other predictors there was only 1 occasion when the observed anomaly range was exceeded. Thus, at Rothamsted more confidence can be placed in the downscaled results from the 2 UKTR decades than in those for the UKHI experiment in the case of temperature. Given that there is little difference between the site and areal changes in mean temperature at this location, that the regression models explain most of the variance in the data and that the most important variable in the regression models is areal temperature, the fact that most of the changes in temperature for UKHI are outside of the anomaly range is not necessarily important

For Seville, however, we can be less confident in the downscaled results, both for mean temperature and precipitation. In the case of mean temperature this is because of a combination of the grid-box changes being outside of the anomaly ranges and of the regression models explaining less of the variance in the observed data compared to Rothamsted. In the case of precipitation, the grid-box changes are within the observed anomaly ranges, but the regression models do not perform as well in explaining the variance of the observed data.

The downscaled changes in temperature and precipitation were then used to perturb the parameters of LARS-WG and 30 yr of daily data were generated for each scenario

\subsection{Scenarios without downscaling}

The regression approach to downscaling described here was very data intensive and so a simpler method of producing climate change scenarios was adopted for the remaining European sites where climate change scenarios were required for crop-climate modelling purposes (e.g. Bindi et al. 1995, Harrison et al. 1995, Iglesias 1995, Wolf et al. 1995). Only results from Athens, Greece, and Jokioincn, Finland, are reported here because of space limitations. For these sites, scenarios were constructed using the appropriate GCM grid-box changes, which were then used to perturb the parameters of LARS-WG and to generate $30 \mathrm{yr}$ of daily data for each scenario.

\subsection{Scenarios incorporating changes in climate variability}

To evaluate the impact of changing variability on crop growth and development, 2 types of daily climate change scenarios were constructed: (1) with, and (2) without changes in climate variability. In the latter scenarios the parameters of LARS-WG were adjusted according to the GCM-derived decadal-mean changes in monthly mean temperature and precipitation intensity. Scenarios including variability could be calculated only from those experiments with daily data available, i.e. UKHI and UKTR decade 66-75. In these scenarios the following set of parameters was adjusted: daily precipitation intensity, duration of dry and wet spells, and means and variances of daily temperature. Changes in these parameters were derived from $10 \mathrm{yr}$ of daily GCM data, the maximum amount available from both UKHI and UKTR, for the appropriate grid box. The daily GCM data from the control and perturbed integrations of the experiment were used in the same way as observed data in the weather generator. The differences between the parameters generated from the control and perturbed integration data were calculated and then applied to the parameters determined using the observed data for each site. Regression downscaling was not applied in this case because of the absence of a robust method for downscaling the coarse resolution variability parameters to the site-specific scale. 


\section{RESULTS}

Results are presented for only the 2 downscaled sites, Rothamsted and Seville, and for Athens and Jokioinen where the effect of the changing variability was also investigated. All of the following tables ( 4 to 11) are based on $30 \mathrm{yr}$ of daily data generated by LARS-WG.

\subsection{Sites including downscaling}

Table 4 illustrates the effect of downscaling on mean monthly precipitation intensity at Rothamsted. Values indicate the change in precipitation intensity $\left(\mathrm{mm} \mathrm{d}^{-1}\right)$ compared to that generated by LARS-WG using para- meters generated from observed daily data (labelled as 'Base' in Tables 4 to 11). Numbers in bold type in Table 4 indicate where the downscaled changes in intensity are of the opposite sign compared to those without downscaling. In all scenarios there appears to be a general decrease in precipitation intensity in summer. For the UKHI scenarios there are 3 instances when downscaling reverses the sign of the change in intensity: in June, August and November downscaling results in a decrease in precipitation intensity, For the UKTR decade 66-75 scenario this occurs twice, in January and May

The effects of downscaling on mean monthly precipitation intensity for Seville are shown in Table 5. There are several occasions when incorporating downscaling results in a reversal of the precipitation intensity

Table 4. Change in mean monthly precipitation intensity $\left(\mathrm{mm} \mathrm{d}^{-1}\right)$ relative to Base at Rothamsted, UK, with and without downscaling. Numbers in bold type indicate where downscaling has resulted in a change of the opposite sign compared to the corre. sponding scenario without downscaling

\begin{tabular}{|c|c|c|c|c|c|c|c|c|c|c|}
\hline & \multirow[t]{2}{*}{ Base } & \multicolumn{6}{|c|}{ Without downscaling } & \multicolumn{3}{|c|}{ With downscaling } \\
\hline & & UKLO & UKHI & $\begin{array}{l}\text { UKTR } \\
31-40\end{array}$ & $\begin{array}{l}\text { UKTR } \\
66-75\end{array}$ & $\begin{array}{l}\text { GFDL } \\
25-34\end{array}$ & $\begin{array}{l}\text { GFDL } \\
55-64\end{array}$ & UKHI & $\begin{array}{l}\text { UKTR } \\
31-40\end{array}$ & $\begin{array}{l}\text { UKTR } \\
66-75\end{array}$ \\
\hline Jan & 3.7 & 1.8 & 2.2 & -0.3 & 0.4 & 0.1 & -0.4 & 1.0 & -0.1 & -0.3 \\
\hline Feb & 3.9 & 1.3 & 1.9 & 1.9 & 1.1 & 0.0 & 0.1 & 1.6 & 1.7 & 0.9 \\
\hline Mar & 2.9 & 1.0 & 1.4 & -0.3 & 0.1 & 0.4 & -0.4 & 1.3 & -0.3 & 0.3 \\
\hline Apr & 3.2 & 1.2 & 0.7 & -0.4 & -0.5 & 0.8 & 0.7 & 0.7 & -0.4 & -0.4 \\
\hline May & 4.3 & 1.2 & -0.4 & 0.0 & 0.3 & 0.0 & 2.2 & -1.8 & 0.0 & -0.3 \\
\hline Jun & 4.5 & -0.5 & 0.2 & -0.4 & 0.2 & 1.3 & 1.8 & -0.2 & -0.8 & 0.0 \\
\hline Jul & 4.2 & 1.4 & -0.1 & -1.3 & -0.5 & 0.6 & -0.6 & -0.1 & -1.3 & -0.4 \\
\hline Aug & 4.4 & 1.3 & 1.7 & -0.7 & -1.4 & -0.5 & -2.1 & -0.3 & -1.5 & -2.6 \\
\hline Sep & 4.2 & 1.3 & 0.3 & -1.0 & -1.0 & 1.1 & -0.4 & 0.1 & -1.3 & -1.3 \\
\hline Oct & 5.1 & 1.1 & 1.2 & 0.7 & 0.6 & 0.5 & -0.3 & 0.7 & 0.5 & 0.3 \\
\hline Nov & 3.9 & 1.1 & 0.0 & 1.2 & 1.3 & 0.1 & -0.1 & -0.1 & -1.5 & 1.7 \\
\hline Dec & 3.4 & 1.2 & 1.3 & -0.1 & 0.4 & -0.1 & 0.6 & 1.5 & 0.0 & 0.4 \\
\hline
\end{tabular}

Table 5. Change in mean monthly precipitation intensity $\left(\mathrm{mm} \mathrm{d}^{-1}\right)$ relative to Base at Seville, Spain, with and without downscaling. Numbers in bold type indicate where downscaling has resulted in a change of the opposite sign compared to the corresponding scenario without downscaling

\begin{tabular}{|c|c|c|c|c|c|c|c|c|c|c|}
\hline & \multirow[t]{2}{*}{ Base } & \multicolumn{6}{|c|}{ Without downscaling } & \multicolumn{3}{|c|}{ With downscaling } \\
\hline & & UKLO & UKHI & $\begin{array}{l}\text { UKTR } \\
31-40\end{array}$ & $\begin{array}{l}\text { UKTR } \\
66-75\end{array}$ & $\begin{array}{l}\text { GFDL } \\
25-34\end{array}$ & $\begin{array}{l}\text { GFDL } \\
55-64\end{array}$ & UKHI & $\begin{array}{l}\text { UKTR } \\
31-40\end{array}$ & $\begin{array}{l}\text { UKTR } \\
66-75\end{array}$ \\
\hline Jan & 8.4 & -1.5 & -6.7 & -1.0 & -2.8 & 0.9 & 1.5 & -3.6 & -0.8 & -1.6 \\
\hline Feb & 8.4 & 0.3 & -6.8 & -2.5 & -0.1 & -0.5 & -0.5 & -0.9 & -0.3 & 2.5 \\
\hline Mar & 6.3 & -0.3 & -5.2 & -1.8 & -1.9 & 0.3 & -0.6 & 1.3 & -0.6 & 0.5 \\
\hline Apr & 5.1 & 0.8 & -0.4 & 3.0 & -0.1 & -1.4 & -0.5 & -0.2 & 1.8 & -0.3 \\
\hline May & 6.1 & 0.6 & -3.1 & 7.4 & -4.7 & -0.8 & -2.3 & -4.1 & 7.2 & -5.0 \\
\hline Jun & 5.3 & -0.5 & -3.5 & -4.8 & -2.2 & 3.0 & -3.4 & -5.3 & -5.3 & -5.3 \\
\hline Jul & 2.2 & 0.1 & -1.1 & -1.5 & -2.2 & -1.1 & -1.3 & 6.4 & 1.4 & 5.1 \\
\hline Aug & 3.3 & -0.7 & -2.6 & -0.7 & -1.4 & -0.4 & -0.8 & -1.6 & -3.3 & -1.0 \\
\hline Sep & 4.9 & -0.3 & -2.9 & -1.4 & -3.3 & 1.1 & -1.1 & 2.4 & 1.4 & 2.6 \\
\hline Oct & 13.9 & 2.2 & -12.2 & -4.0 & -1.7 & 4.5 & -3.9 & 8.2 & 3.3 & 8.2 \\
\hline Nov & 11.8 & 1.6 & -7.8 & -1.8 & -7.9 & 3.6 & 1.2 & 1.5 & 1.5 & -0.8 \\
\hline Dec & 10.5 & -0.3 & -6.5 & -1.8 & -3.6 & -1.9 & 0.0 & -3.4 & -1.3 & -2.3 \\
\hline
\end{tabular}


change. In all these cases a decrease in precipitation intensity becomes an increase as a result of downscaling. This occurs in July, September and October for both the UKHI and UKTR experiments. In these months the performance of the regression models was suspect and, hence, these results should be treated with caution

Changes in mean temperature relative to the generated base at Rothamsted are illustrated in Table 6 for each climate change scenario. Downscaling generally appears to result in higher mean temperatures at this site. All scenarios indicate warming in all months with only 2 exceptions: the early decade of the UKTR experiment exhibits a temperature decrease in December in both the downscaled and simple scenarios, and the GFDL decade 25-34 shows a decrease in November. The UKTR decade 31-40 scenario also exhibits an anomalously high warming in February which is a result of the internal variability of the GCM. This is present for only a few years and over a limited geographical area. This highlights the problem of defining a greenhouse gas signal from the noise of natural variability in the model.

Changes in mean temperatures relative to the generated base for each scenario at Seville are presented in Table 7 As was the case with Rothamsted, downscaling generally tends to increase the mean temperatures at this site. All scenarios indicate increases in mean temperature, apart from the earlier decade of the GFDL experiment in December, when there is a small decrease in mean temperature.

\subsection{Sites without downscaling}

For these scenarios, the grid-box changes for each of the GCMs were extracted and used to perturb the weather generator parameters for each site. Analysis of

Table 6. Changes in mean temperature $\left({ }^{\circ} \mathrm{C}\right)$ relative to Base at Rothamsted with and without downscaling

\begin{tabular}{|c|c|c|c|c|c|c|c|c|c|c|}
\hline & \multirow[t]{2}{*}{ Base } & \multicolumn{6}{|c|}{ Without downscaling } & \multicolumn{3}{|c|}{ With downscaling } \\
\hline & & UKLO & UKHI & $\begin{array}{l}\text { UKTR } \\
31-40\end{array}$ & $\begin{array}{l}\text { UKTR } \\
66-75\end{array}$ & $\begin{array}{l}\text { GFDL } \\
25-34\end{array}$ & $\begin{array}{l}\text { GFDL } \\
55-64\end{array}$ & UKHI & $\begin{array}{l}\text { UKTR } \\
31-40\end{array}$ & $\begin{array}{r}\text { UKTR } \\
66-75\end{array}$ \\
\hline Jan & 1.9 & 5.4 & 8.2 & 0.5 & 3.5 & 0.8 & 2.3 & 8.3 & 0.5 & 3.5 \\
\hline Feb & 3.1 & 5.2 & 6.7 & 7.0 & 1.0 & 0.4 & 1.4 & 7.0 & 7.2 & 1.0 \\
\hline Mar & 5.3 & 5.4 & 5.3 & 0.8 & 2.4 & 0.3 & 1.4 & 5.6 & 0.7 & 2.5 \\
\hline Apr & 7.7 & 5.8 & 3.9 & 0.9 & 0.6 & 1.3 & 1.9 & 3.7 & 0.8 & 0.5 \\
\hline May & 10.9 & 5.6 & 4.1 & 0.6 & 1.6 & 0.3 & 1.5 & 4.8 & 0.8 & 1.9 \\
\hline Jun & 13.8 & 5.6 & 3.0 & 1.3 & 1.5 & 0.5 & 1.1 & 3.4 & 1.7 & 1.6 \\
\hline Jul & 15.4 & 5.6 & 3.5 & 0.8 & 2.2 & 0.4 & 2.2 & 3.7 & 0.9 & 2.3 \\
\hline Aug & 15.7 & 5.5 & 4.9 & 1.9 & 3.7 & 1.2 & 2.3 & 5.2 & 2.0 & 3.7 \\
\hline Sep & 13.7 & 5.4 & 4.5 & 2.0 & 3.8 & 0.1 & 2.3 & 4.7 & 2.0 & 3.8 \\
\hline Oct & 9.9 & 5.4 & 4.0 & 0.7 & 1.5 & 1.2 & 1.6 & 4.1 & 0.7 & 1.5 \\
\hline Nov & 5.7 & 5.4 & 2.9 & 1.6 & 2.0 & -0.1 & 2.2 & 3.0 & 1.5 & 2.0 \\
\hline Dec & 3.0 & 5.3 & 4.3 & -0.9 & 2.3 & 0.5 & 2.5 & 4.7 & -0.9 & 2.3 \\
\hline
\end{tabular}

Table 7. Changes in mean temperature $\left({ }^{\circ} \mathrm{C}\right)$ relative to Base at Seville with and without downscaling

\begin{tabular}{|c|c|c|c|c|c|c|c|c|c|c|}
\hline & \multirow[t]{2}{*}{ Base } & \multicolumn{6}{|c|}{ Without downscaling } & \multicolumn{3}{|c|}{ With downscaling } \\
\hline & & UKLO & UKHI & $\begin{array}{l}\text { UKTR } \\
31-40\end{array}$ & $\begin{array}{l}\text { UKTR } \\
66-75\end{array}$ & $\begin{array}{l}\text { GFDL } \\
25-34\end{array}$ & $\begin{array}{l}\text { GFDL } \\
55-64\end{array}$ & UKHI & $\begin{array}{l}\text { UKTR } \\
31-40\end{array}$ & $\begin{array}{l}\text { UKTR } \\
66-75\end{array}$ \\
\hline Jan & 9.8 & 4.6 & 4.4 & 1.8 & 2.3 & 1.1 & 3.0 & 5.1 & 2.3 & 2.8 \\
\hline Feb & 11.6 & 4.6 & 6.0 & 2.2 & 3.9 & 1.7 & 0.9 & 6.8 & 2.5 & 4.5 \\
\hline Mar & 13.1 & 4.5 & 6.2 & 0.6 & 2.4 & 1.2 & 2.6 & 7.1 & 0.6 & 2.7 \\
\hline Apr & 15.4 & 4.4 & 5.4 & 1.4 & 1.5 & 0.7 & 1.8 & 4.8 & 1.2 & 1.3 \\
\hline May & 19.0 & 4.3 & 5.4 & 1.0 & 2.7 & 0.7 & 2.3 & 5.6 & 1.2 & 2.7 \\
\hline Jun & 23.1 & 4.0 & 7.2 & 3.9 & 4.4 & 1.2 & 5.7 & 7.5 & 4.0 & 4.6 \\
\hline Jul & 26.6 & 4.2 & 6.5 & 3.1 & 4.9 & 1.4 & 5.5 & 7.8 & 3.5 & 5.8 \\
\hline Aug & 27.2 & 4.4 & 6.4 & 2.1 & 5.3 & 0.2 & 3.1 & 6.8 & 2.4 & 5.7 \\
\hline Sep & 24.7 & 4.5 & 6.6 & 2.2 & 6.5 & 0.1 & 3.4 & 7.0 & 2.4 & 6.9 \\
\hline oct & 19.4 & 4.7 & 7.3 & 2.7 & 4.6 & 1.3 & 2.3 & 8.0 & 2.9 & 5.1 \\
\hline Nov & 14.0 & 4.5 & 5.5 & 2.1 & 3.2 & 0.2 & 2.1 & 7.2 & 2.8 & 4.3 \\
\hline Dec & 10.4 & 4.5 & 5.6 & 0.2 & 1.7 & -0.3 & 3.2 & 7.5 & 0.4 & 2.3 \\
\hline
\end{tabular}


the daily GCM data from UKHI and the last decade of the UKTR experiment permitted the inclusion of changes in temperature variability and in wet and dry spell lengths. Where no changes in variability were imposed, the number of wet days and the length of the wet and dry spells remained the same as in the observed case. This meant that increases in precipitation amount resulted from increases in precipitation intensity, rather than from an increase in the number of wet days in a given month. Where changes in variability were included, the length of wet and dry spells were changed and, consequently, the number of wet days. In this case increases in precipitation amount may have been spread over more days in the month in addition to possible changes in precipitation intensity.

Changing the variability of temperature and precipitation should not lead to changes in the mean values of these variables, but only to changes in the frequency of particular values occurring. Table 8 indicates the change in mean monthly precipitation intensity $(\mathrm{mm}$ $\mathrm{d}^{-1}$ ) compared to the generated base at Jokioinen for the climate change scenarios with and without changes in climate variability. It is apparent from this table that there are differences between the mean precipitation intensity changes as a result of including changes in variability. These differences may be explained as follows. First, the scenarios with and without variability were constructed in slightly different ways. For the scenarios incorporating variability changes, the changes in precipitation intensity applied to the parameters of LARS-WG were calculated from daily GCM data and were changes in precipitation

Table 8 . Change in mean monthly precipitation intensity (mm $\mathrm{d}^{-1}$ ) relative to Base at Jokioinen, Finland, with and without changes in variability. Numbers in bold type indicate where the inclusion of changes in variability has resulted in a change of the opposite sign compared to the corresponding scenario without changes in variability

\begin{tabular}{|c|c|c|c|c|c|}
\hline & \multirow[t]{2}{*}{ Base } & \multicolumn{2}{|c|}{$\begin{array}{l}\text { No change } \\
\text { in variability }\end{array}$} & \multicolumn{2}{|c|}{$\begin{array}{c}\text { With variability } \\
\text { changes }\end{array}$} \\
\hline & & UKHI & $\begin{array}{l}\text { UKTR } \\
66-75\end{array}$ & UKHI & $\begin{array}{l}\text { UKTR } \\
66-75\end{array}$ \\
\hline Jan & 2.2 & 2.0 & 0.0 & 2.0 & 0.4 \\
\hline Feb & 2.1 & 1.4 & 0.4 & 0.6 & 0.1 \\
\hline Mar & 2.6 & 1.7 & 0.9 & 1.1 & 0.6 \\
\hline $\mathrm{Apr}$ & 2.5 & 2.5 & 0.6 & 1.6 & 1.4 \\
\hline May & 3.6 & 0.6 & 0.8 & 3.4 & 1.1 \\
\hline Jun & 4.4 & 0.8 & 2.2 & 3.2 & 1.9 \\
\hline Jul & 5.6 & 2.5 & 0.1 & 1.2 & 1.1 \\
\hline Aug & 6.1 & 0.1 & 0.7 & 2.8 & 4.8 \\
\hline Sep & 5.1 & 1.4 & -0.2 & -0.4 & 0.1 \\
\hline Oct & 4.5 & 2.9 & 0.9 & 1.3 & 0.1 \\
\hline Nov & 3.3 & 1.1 & 0.6 & 1.9 & 0.5 \\
\hline Dec & 2.9 & 2.5 & 1.2 & 1.9 & 0.8 \\
\hline
\end{tabular}

intensity on wet days. For the scenarios without variability changes, the intensity changes were taken directly from monthly GCM data and although in units of $\mathrm{mm} \mathrm{d}^{-1}$, they apply to all days rather than just wet days. For this reason alone, one would not expect the intensity changes to be the same. Second, the changes in precipitation intensity indicated in Table 8 are changes in intensity on wet days, and since the number of wet days changes in the scenario incorporating variability changes one would not necessarily expect the changes to be the same as in the scenarios without variability changes. Table 8 indicates that these differences in scenario construction have resulted, in some months, in increases in precipitation intensities from scenarios including variability changes compared to decreases in the scenario with only mean changes (for example, May, June, July and August in the case of UKHI and September in the case of UKTR). A similar situation exists at Athens (see Table 9).

The effects of changes in variability on mean and minimum temperatures for Jokioinen are illustrated in Table 10. It is apparent from Table $10 \mathrm{a}$ that the agreement in mean temperature for both the UKHI and UKTR scenarios with and without variability changes is relatively good, as it should be. Temperature is dependent on precipitation in LARS-WG, i.e. on whether a day is wet or dry, so the changing number of wet days in the scenarios incorporating changes in variability most probably accounts for the slight differences in the means illustrated in Table $10 \mathrm{a}$. The largest differences $\left(1{ }^{\circ} \mathrm{C}\right)$ occur in January and November of the UKHI scenarios. Examination of Table $10 \mathrm{~b}$ indi-

Table 9. Change in mean monthly precipitation intensity (mm $\mathrm{d}^{-1}$ ) relative to Base at Athens, Greece, with and without changes in variability. Numbers in bold type indicate where the inclusion of changes in variability has resulted in a change of the opposite sign compared to the corresponding scenario without changes in variability

\begin{tabular}{|lrrrrr|}
\hline & Base & \multicolumn{2}{c}{$\begin{array}{c}\text { No change } \\
\text { in variability }\end{array}$} & \multicolumn{2}{c|}{$\begin{array}{c}\text { With variability } \\
\text { changes }\end{array}$} \\
& & UKHI & UKTR & UKHI & UKTR \\
& & & $66-75$ & & $66-75$ \\
\hline Jan & 4.7 & -0.7 & -0.3 & 1.6 & $\mathbf{1 . 4}$ \\
Feb & 6.9 & -3.1 & -0.9 & -2.9 & -2.2 \\
Mar & 6.7 & -2.6 & -2.1 & -2.9 & -0.6 \\
Apr & 4.4 & -1.4 & 0.1 & -0.6 & 1.9 \\
May & 3.4 & -0.9 & 0.0 & 1.6 & 0.0 \\
Jun & 4.7 & -1.8 & -0.8 & -0.1 & -0.4 \\
Jul & 5.9 & -2.1 & -3.0 & 1.0 & -2.6 \\
Aug & 5.3 & -0.5 & -2.0 & $\mathbf{0 . 4}$ & -0.7 \\
Sep & 5.3 & -1.2 & -2.0 & 1.4 & $\mathbf{0 . 7}$ \\
Oct & 8.7 & 0.5 & -1.3 & $-\mathbf{0 . 2}$ & -1.8 \\
Nov & 7.4 & 1.8 & -2.3 & 1.2 & -1.9 \\
Dec & 6.4 & 0.0 & -1.5 & -0.7 & -0.6 \\
& & & & & \\
\hline
\end{tabular}


Table 10. Jokioinen: (a) Mean temperature $\left({ }^{\circ} \mathrm{C}\right)$ with and without changes in variability. (b) Mean number of days per month with $T_{\min }<0^{\circ} \mathrm{C}$

\begin{tabular}{|c|c|c|c|c|c|}
\hline & \multirow[t]{2}{*}{ Base } & \multicolumn{2}{|c|}{$\begin{array}{l}\text { No change } \\
\text { in variability }\end{array}$} & \multicolumn{2}{|c|}{$\begin{array}{c}\text { With variability } \\
\text { changes }\end{array}$} \\
\hline & & UKHJ & UKTR & UKHI & UKTR \\
\hline \multicolumn{6}{|c|}{ (a) Mean temperature $\left({ }^{\circ} \mathrm{C}\right)$} \\
\hline Jan & -9.4 & -0.1 & -5.2 & 0.9 & -5.4 \\
\hline Feb & -9.6 & -3.3 & -4.8 & -3.3 & -4.3 \\
\hline Mar & -4.4 & 3.6 & -0.2 & 2.8 & -0.4 \\
\hline Apr & 2.1 & 10.1 & 4.7 & 9.9 & 4.6 \\
\hline May & 8.7 & 17.1 & 12.7 & 17.3 & 11.8 \\
\hline Jun & 13.3 & 17.8 & 15.1 & 17.0 & 14.8 \\
\hline Jul & 15.6 & 19.4 & 18.0 & 18.9 & 17.9 \\
\hline Aug & 13.9 & 17.5 & 15.7 & 17.3 & 15.8 \\
\hline Sep & 9.1 & 12.3 & 10.6 & 12.5 & 10.5 \\
\hline Oct & 3.5 & 12.4 & 8.4 & 12.4 & 8.8 \\
\hline Nov & -1.5 & 8.0 & 1.9 & 7.0 & 2.4 \\
\hline Dec & -6.6 & 1.7 & -0.3 & 1.4 & -1.1 \\
\hline \multicolumn{6}{|c|}{ (b) No. of days with $T_{\min }<0^{\circ} \mathrm{C}$} \\
\hline Jan & 30.8 & 22.0 & 28.6 & 20.0 & 27.8 \\
\hline Feb & 27.5 & 23.6 & 25.4 & 23.8 & 26.8 \\
\hline Mar & 30.3 & 15.2 & 24.4 & 16.3 & 26.3 \\
\hline Apr & 23.0 & 4.9 & 16.8 & 3.5 & 15.8 \\
\hline May & 5.3 & 0.0 & 0.7 & 0.0 & 3.8 \\
\hline Jun & 0.5 & 0.0 & 0.1 & 0.5 & 0.9 \\
\hline Jul & 0.0 & 0.0 & 0.0 & 0.0 & 0.0 \\
\hline Aug & 0.3 & 0.0 & 0.0 & 0.0 & 0.2 \\
\hline Sep & 3.8 & 1.0 & 2.0 & 0.6 & 2.2 \\
\hline Oct & 14.7 & 0.6 & 3.4 & 2.1 & 2.0 \\
\hline Nov & 26.0 & 3.9 & 17.5 & 10.9 & 16.6 \\
\hline Dec & 30.2 & 18.3 & 22.2 & 18.2 & 22.6 \\
\hline
\end{tabular}

cates how changes in variability affect the number of days in a month when minimum temperature is below $0^{\circ} \mathrm{C}$. In the UKHI scenario including variability changes, more days on average have minimum temperatures below $0^{\circ} \mathrm{C}$ in February, March, October and November than in the scenario incorporating only mean changes. The frost season is more severe in May and June [i.e. more days on average with minimum temperature $\left(T_{\text {min }}\right)<0^{\circ} \mathrm{C}$ ] and begins again in August rather than September in the UKTR scenario with variability changes applied.

Finally, Table 11 compares mean temperatures and the mean number of days when maximum temperature exceeds $30^{\circ} \mathrm{C}$ at Athens. There is little difference between mean temperature for the scenarios with and without variability (Table 11a); the largest difference $\left(1.1^{\circ} \mathrm{C}\right)$ occurs in January in the UKHI scenario, but generally differences are less than half this value. In both the UKHI and UKTR scenarios without variability the maximum temperatures in excess of $30^{\circ} \mathrm{C}$ generally occur between April and October (Table 11b). Incorporating changes in variability, however, indicates that this maximum temperature would, on aver-
Table 11. Athens: (a) Mean temperature $\left({ }^{\circ} \mathrm{C}\right)$ with and without changes in variability. (b) Mean number of days per month with $T_{\max }>30^{\circ} \mathrm{C}$

\begin{tabular}{|c|c|c|c|c|c|}
\hline & \multirow[t]{2}{*}{ Base } & \multicolumn{2}{|c|}{$\begin{array}{l}\text { No change } \\
\text { in variability }\end{array}$} & \multicolumn{2}{|c|}{$\begin{array}{c}\text { With variability } \\
\text { changes }\end{array}$} \\
\hline & & UKHI & UKTR & UKHI & UKTR \\
\hline \multicolumn{6}{|c|}{ (a) Mean temperature $\left({ }^{\circ} \mathrm{C}\right)$} \\
\hline Jan & 9.3 & 12.0 & 10.6 & 10.9 & 10.5 \\
\hline Feb & 10.0 & 12.5 & 11.1 & 12.3 & 11.3 \\
\hline Mar & 12.2 & 14.6 & 13.3 & 14.4 & 13.5 \\
\hline Apr & 15.9 & 18.8 & 17.3 & 18.9 & 17.0 \\
\hline May & 20.5 & 23.5 & 21.8 & 23.6 & 21.6 \\
\hline Jun & 24.9 & 28.1 & 26.6 & 28.4 & 26.7 \\
\hline Jul & 27.6 & 30.9 & 29.2 & 30.9 & 29.3 \\
\hline Aug & 27.2 & 30.8 & 29.5 & 30.7 & 29.3 \\
\hline Sep & 23.3 & 26.9 & 25.1 & 27.5 & 25.9 \\
\hline Oct & 19.1 & 22.8 & 20.6 & 22.7 & 20.4 \\
\hline Nov & 14.3 & 17.9 & 15.9 & 18.1 & 16.4 \\
\hline Dec & 11.1 & 14.3 & 12.7 & 14.2 & 12.6 \\
\hline \multicolumn{6}{|c|}{ (b) No. of days with $T_{\max }>30^{\circ} \mathrm{C}$} \\
\hline Jan & 0.0 & 0.0 & 0.0 & 0.5 & 0.2 \\
\hline Feb & 0.0 & 0.0 & 0.0 & 0.2 & 0.0 \\
\hline Mar & 0.0 & 0.0 & 0.0 & 0.6 & 0.8 \\
\hline Apr & 0.0 & 0.7 & 0.2 & 0.8 & 1.7 \\
\hline May & 2.9 & 9.0 & 4.7 & 9.5 & 5.2 \\
\hline Jun & 14.3 & 24.4 & 20.7 & 26.6 & 20.2 \\
\hline Jul & 26.0 & 30.7 & 29.4 & 30.9 & 29.8 \\
\hline Aug & 24.8 & 30.3 & 29.2 & 30.8 & 27.1 \\
\hline Sep & 8.6 & 20.3 & 14.4 & 24.6 & 17.1 \\
\hline Oct & 2.0 & 7.4 & 3.3 & 7.0 & 5.5 \\
\hline Nov & 0.0 & 0.2 & 0.0 & 0.8 & 0.1 \\
\hline Dec & 0.0 & 0.0 & 0.0 & 0.3 & 0.0 \\
\hline
\end{tabular}

age, be exceeded at some time in almost all months of the year.

\section{CONCLUSIONS}

This paper has demonstrated a variety of methods for constructing scenarios of climate change at both the broad and site-specific scales for use in crop-climate modelling. There are 4 stages in the process of constructing climate change scenarios described here and each stage contributes to the final range of scenarios produced:

(1) Selection of the GCM experiment. Which GCM should be used? Does any one GCM perform better than other GCM experiments? A number of GCM experiments were used here in order to indicate a range of available results, and also to show how the ongoing development over time of one GCM leads to different results. Although more confidence may be placed in those GCMs which more adequately simulate observed climate in their control integrations, no one GCM can be said to accurately simulate future cli- 
mate. None of the GCM experiments used here included the effects of sulphate aerosols on the radiative forcing of climate. Recent results indicate that the patterns of greenhouse gas-induced warming are altered significantly when the effects of sulphate aerosols are included (Mitchell et al. 1995).

(2) Production of high spatial resolution. Should downscaling be used, or should GCM changes be applied directly to the observed station data? One downscaling technique, multiple regression, and its impacts on the final scenario at 2 sites in Europe are described in this paper. These examples indicate the problems which may arise in calculating regression relationships between site- and large-scale climate How much confidence is placed in the results from downscaling depends on the performance of the regression models in capturing the variability of the observed data, whether or not the GCM-derived changes lie within the observed data range used to calibrate the equations, and on the quality of the observed data used to construct large-scale means.

(3) Production of high temporal resolution. Scenario data at the daily time step required by crop-climate modellers were generated using a stochastic weather generator. A weather generator is a computationally inexpensive way to construct climate change scenarios which (i) are long enough to be used in agricultural risk assessment, and (ii) allow incorporation of changes in the weather statistics important for crop simulation models, e.g. climate variability. An alternative method is to apply GCM-derived changes directly to an observed record of daily data. The method used here introduces more uncertainty into the climate change scenarios since the weather generator must first be shown to perform satisfactorily at the sites concerned. Ideally, a weather generator should be tuned to each site at which it is used, but because of the extra time and data that this would require it is not always possible to do so. Most often, weather generators are calibrated using about 20 yr of daily data and then the statistics of the simulated data are compared with those of the observed data. If the weather generator is considered to perform adequately it is usually used without any modifications

(4) Incorporation of changes in variability. Katz \& Brown (1992) have shown that changes in variability are more important than changes in mean values when considering the frequency of extreme events, and for this reason crop modellers consider it important to include variability changes in scenarios of climate change. In this work, variability changes were calculated from $10 \mathrm{yr}$ of daily GCM data. As mentioned earlier, GCMs often exhibit substantial medium-term climate variability which may result in their climate statistics differing greatly between successive decades.
This implies that variability may change significantly on the decadal timescale for reasons unrelated to greenhouse gas forcing, and to obtain a more reliable estimate of these changes a longer time period from the GCM should be used.

To construct the scenarios described here both equilibrium and transient GCM experiments were used. Scenarios based on equilibrium climate change experiments are not indicative of climate in the near future, but they can be used to determine the likely range of changes in climate that may occur towards the end of the 21st century and beyond, depending on future greenhouse gas emissions. Transient climate change experiments, however, enable us to examine the pattern and magnitude of climate change in response to a continuous change in forcing, for example, a $1 \% \mathrm{yr}^{-1}$ compound increase in atmospheric $\mathrm{CO}_{2}$ concentration.

Site-specific scenarios were produced using downscaling techniques and also a simpler method using GCM grid-box changes directly. Both methods were used in conjunction with the LARS-WG stochastic weather generator. The GCM-derived changes were applied directly to the parameters of the weather generator. The latter approach allowed the investigation of the effect of changes in climate variability on agricultural production and agricultural risk in Europe (Semenov et al. 1996). Downscaling involved the determination of regression relationships between the broad-scale and site-specific climate. These relationships were then used to determine the site changes in temperature and precipitation by using the GCM gridbox changes as predictors. Downscaling of temperature was more successful than for precipitation; precipitation was especially problematic for Seville in summer. The disadvantage of the regression downscaling technique is that it is very data intensive; observed data from several sites are required in order to calculate observed areal anomalies. For the rest of the sites in Europe climate change scenarios were produced without downscaling. For those GCMs where daily data were available for the appropriate climate variables, climate change scenarios with and without changes in variability were constructed. The variability of climate has important effects on the occurrence of extreme events as demonstrated here for Jokioinen and Athens, which may have more of an impact on crop growth than changes in mean climate alone (Semenov \& Porter 1995, see also discussion in Semenov et al. 1996).

In the future, construction of site-specific scenarios of climate change may be aided by the current development of the high resolution limited area models (HRLAMs; e.g. Jones et al. 1995). These models are embedded within GCMs and operate at a resolution of approximately $50 \mathrm{~km}$. Validation of the HRLAMs will 
indicate whether these results are more reliable than those from GCMs and whether they can be used alone to produce more robust local scenarios of climate change. One recent study has shown, however, that there may be large differences between such model results and observed weather statistics, especially in the case of climate variability (Mearns et al. 1995a, b). This implies that at present the output from such models cannot be used directly as climate change scenarios and, hence, the need for downscaling techniques and local stochastic weather generators in climate change studies may remain in the near future.

Acknowledgements. The UK Meteorological Office GCM data were provided by the Climate Impacts LINK Project (Department of the Environment Contract EPG 1/1/16) on behalf of the UK Meteorological Office. The GFDL data were provided by Dr R. J. Stouffer of the Geophysical Fluid. Dynamics Laboratory at Princeton University, USA. We thank the Finnish Meteorological Institute for providing data for Jokioinen and those colleaques invoived in this project who supplied climate data from their own countries. This work was funded by the Commission of the European Communities' Environment Programme (Contract EV5V-CT93-294). Valuable comments were also provided by 2 anonymous referees.

\section{LITERATURE CITED}

Bardossy A (1994) Downscaling from GCMs to local climate through stochastic linkages. In: Paoli $G$ (ed) Climate change, uncertainty and decision making. Institute for Risk Research, Waterloo, p 3-6

Bardossy A, Caspary HJ (1991) Conceptual model for the calculation of the regional hydrologic effects of climate change. In: Hydrology for the water management of large river basins. Proceedings of the Vienna Symposium, August 1991. IAHS Publ no. 201

Barrow EM, Semenov MA (1995) Climate change scenarios with high spatial and temporal resolution for agricultural applications. Forestry 68:349-360

Bindi M, Fibbi L, Gozzini B, Orlandini S, Miglietta F (1995) Effects on grapevine. In: Harrison PA, Butterfield RE, Downing TE (eds) Climate change and agriculture in Europe: assessment of impacts and adaptations. Research Report No. 9, Environmental Change Unit, University of Oxford, p 206-220

Carter TR, Parry ML, Harasawa H, Nishioka S (1994) IPCC technical guidelines for assessing climate change impacts and adaptations. UCL/CGER (University College London/ Center for Global Environmental Research), London/Tsukuba

Harrison PA, Butterfield RE, Gawith MJ (1995) Effects on winter wheat, sunflower, onion and grassland in Europe. In: Harrison PA, Butterfield RE, Downing TE (eds) Climate change and agriculture in Europe: assessment of impacts and adaptations. Research Report No. 9, Environmental Change Unit, University of Oxford, p 330-385

Hasselmann K, Sausen R, Maier-Reimer E, Voss R (1993) On the cold start problem in transient simulations with coupled atmosphere-ocean models. Clim Dyn 9:53-61

Hay LE, McCabe GJ, Wolock DM, Ayers MA (1992) Use of weather types to disaggregate general circulation model predictions. J Geophys Res 97:2781-2790

Hulme M (1994) Validation of large-scale precipitation fields in global circulation models. In: Desbois M, Désalmand F (eds) Global precipitation and climate change. NATO ASI series, Springer-Verlag, Berlin, p 387-405

Hulme M, Briffa KR, Jones PD, Senior CA (1993) Validation of GCM control simulations using indices of daily airflow types over the British Isles. Clim Dyr 9:95-105

Hulme M, Conway D, Jones PD, Jiang T, Barrow EM, Turney $C$ (1995) Construction of a 1961-90 European climatology for climate change modelling and impact applications. Int J Climatol 15:1333-1363

Iglesias A (1995) Effects on maize. In: Harrison PA, Butterfield RE, Downing, TE (eds) Climate change and agriculture in Europe: assessment of impacts and adaptations. Research Report No. 9, Environmental Change Unit, University of Oxford, p 223-231

IPCC (1996) Climate change 1995: the science of climate change. Houghton JT, Meira Filho LG, Callander BA, Kattenberg $A_{1}$ Maskell $K$ (eds). Cambridge University Press, Cambridge

Jones PD, Conway D (1995) The use of weather types for GCM downscaling. In: Proceedings of 6th Internationa! Meeting on Statistical Climatology, University College, Galway, Ireland, June 1995, p 193-196

Jones RG, Murphy JM, Noguer M (1995) Simulation of climate change over Europe using a nested regional climate model. Part 1: Assessment of control climate, including sensitivity to location of lateral boundaries. Q J R Meteorol Soc 121:1413-1449

Karl TR, Wang WC, Schlesinger ME, Knight RW, Portman D (1990) A method of relating general circulation model simulated climate to the observed local climate. Part I: Seasonal statistics. J Clim 3:1063-1079

Kattenberg A, Giorgi F, Grassl H, Meehl GA, Mitchell JFB, Stouffer RJ, Tokioka T, Weaver AJ, Wigley TML (1996) Climate models-projections of future climate. In: Houghton JT, Meira Filho LG, Callander BA, Harris N, Kattenberg A, Maskell K (eds) Climate change 1995: the science of climate change. Cambridge University Press, Cambridge, p 285-357

Katz RW, Brown BG (1992) Extreme events in a changing climate: variability is more important than averages. Clim Change 21:289-302

Kenny GJ, Harrison PA, Parry ML (eds) (1993) The effect of climate change on agricultural and horticultural potential in Europe. Research Report No. 2, Environmental Change Unit, University of Oxford

Kim JW, Chang JT, Baker NL, Wilks DS, Gates WL (1.984) The statistical problem of climate inversion: determination of the relationship between local and large-scale climate. Mon Weather Rev 112:2069-2077

Manabe S, Spelman MJ, Stouffer RJ (1992) Transient responses of a coupled ocean-atmosphere model to gradual changes of atmospheric $\mathrm{CO}_{2}$. Part II: Seasonal response. J Clim 5:105-126

Manabe S, Stouffer RJ, Spelman MJ, Bryan K (1991) Transient responses of a coupled ocean-atmosphere model to gradual changes of atmospheric $\mathrm{CO}_{2}$. Part [: Annual mean response. J Clim 4:785-818

Matyasovszky I, Bogardi I, Bardossy A, Duckstein L (1993) Space-time precipitation reflecting climate change. Hydrol Sci J 38:539-558

Mearns LO, Giorgi F, McDaniel L, Shields C (1995a) Analysis of variability and diurnal range of daily temperature in a nested regional climate model: comparison with observations and doubled $\mathrm{CO}_{2}$ results. Clim Dyn 11:193-209 
Mearns L.O, Giorgi F. McDaniel L, Shjelds C (1995b) Analysis of daily variability of precipitation in a nested regional climate model: comparison with observations and doubled $\mathrm{CO}_{2}$ results. Global Planet Change 10:55-78

Mearns LO, Rosenzweig C, Goldberg R (1992) The effect of changes in climatic variability on CERES-wheat yields sensitivity and $2 \times \mathrm{CO}_{2}$ General Circulation Model studies Agric For Meteor 62:159-189

Mearns LO, Rosenzweig C, Goldberg R (1996) The effect of changes in daily and interannual climatic variability on CERES-wheat yields. A sensitivity study. Clim Change 32 : $257-292$

Mitchell JFB, Johns TC, Gregory JM, Tett SFB (1995) Climate response to increasing levels of greenhouse gases and sulphate aerosols. Nature 376:501-504

Mitchell JFB, Manabe S, Meleshko V, Tokioka T (1990) Equilibrium climate change - and its implications for the future. In: Houghton JT, Jenkins GJ, Ephraums JJ (eds) Climate change: the IPCC scientific assessment. Cambridge University Press, Cambridge, p 131-172

Murphy JM (1995) Transient response of the Hadley Centre coupled ocean-atmosphere model to increasing carbon dioxide. Part I: Control climate and flux adjustment. J Clim 8:36-56

Murphy JM, Mitchell JFB (1995) Transient response of the Hadley Centre coupled ocean-atmosphere model to increasing carbon dioxide. Part II: Spatial and temporal structure of the response. J Clim 8:57-80

Racsko P, Szeidl L, Semenov M (1991) A serial approach to local stochastic weather models. Ecol Model 57:27-41

Santer BD (1988) Regional validation of general circulation models. PhD thesis, Climatic Research Unit Publication No. 9, Norwich

Semenov MA, Barrow EM (1997) Use of a stochastic weather generator in the development of climate change scenarios.

Editor: G. Esser, Gießen, Germany
Clim Change (in press)

Semenov MA, Porter JR (1994) The implications and importance of non-linear responses in modelling of growth and development of wheat. In: Grasman J, van Straten G (eds) Predictability and non-linear modelling in natural sciences and economics. Pudoc. Wageningen

Semenov MA, Porter JR (1995) Climatic varability and the modelling of crop yields. Agric For Meteorol 73: 265--283

Semenov MA, Wolf J, Evans LG, Eckersten H, Iglesias A. Porter JR (1996) Comparison of wheat models under climate change: ll. Application of climate change scenarios. Clim Res 7:271-281

Viner D, Hulme M (1993) The U.K. Meteorological Office high resolution GCM transient experiment (UKTR). Technical Note 4 prepared for the U.K. Department of the Environment Climate Change Impacts/Predictive Modelling LINK, Contract Reference Number PECD 7/12/96. Climatic Research Unit, Norwich

von Storch H, Zorita E, Cubasch U (1993) Downscaling of global climate change estimates to regional scales: an application to Iberian rainfall in wintertime. J Clim 6 : 1161-1171

Wigley TML, Jones PD, Briffa KR, Smith G (1990) Obtaining sub-grid-scale information from coarse-resolution general circulation model output. J Geophys Res 95: 1943-1953

Wilson CA, Mitchell JFB (1987) Simulated climate and $\mathrm{CO}_{2}$ induced climate change over Western Europe Clim Change 10:11-42

Wolf J, Semenov MA, Eckersten H. Evans LG, Iglesias A, Porter JR (1995). Effects on winter wheat: a comparison of five models. In: Harrison PA, Butterfield RE, Downing TE (eds) Climate change and agriculture in Europe: assessment of impacts and adaptations. Research Report No.9, Environmental Change Unit, University of Oxford, $p$ $231-280$

Manuscript first received: February 6, 1996 Revised version accepted: September 2, 1996 